\title{
A Study on Agriculture Informatics in Indian Context
}

\author{
K.Anji Reddy \\ Senior Assistant Professor \\ Dept. of Computer Applications \\ V.R. Siddhartha Engineering \\ College \\ Vijayawada-7
}

\author{
J.Rajendra Prasad, PhD. \\ Professor and Head \\ Dept. of Information \\ Technology \\ P.V.P.Siddhartha Institute of \\ Technology \\ Vijayawada-7
}

\author{
K.Parish Venkata Kumar \\ Assistant Professor \\ Dept. of Computer Applications \\ V.R. Siddhartha Engineering \\ College \\ Vijayawada-7
}

\begin{abstract}
Since India has a strong agriculture base and agriculture being the field of high developmental priority, the creation of a suitable Computational Agriculture Information System has become essential as development of agricultural sector is a potential catalyst for socio-economic development. The real test of technological development is whether it reaches people and the most important task is to produce, manage and deliver relevant information systems appropriately that are useful for the society. So, there is a need to locally develop information systems which are based on local needs and structures. That is why a country like India needs to adopt and develop information systems based on its own needs and structures, using their own methods and practices in the areas like healthcare, agriculture, education etc.

Some of the problems faced towards informatics development for agriculture in India are:

- Unavailability of appropriate Agriculture Information Systems to facilitate Agriculture Informatics suitable to the Indian requirements.

- Scarcity of experienced indigenous systems development resources capable of producing suitable information systems for the Agriculture sector.
\end{abstract}

This paper primarily focuses on developing Computational Agriculture Information System

\section{Keywords}

Agriculture, Information System, Agriculture Informatics, Decision Support System.

\section{INTRODUCTION}

In any sector, information is the key for its development. Agriculture is not exception to it. If the relevant and right information in right time is provided, it can help agriculture a lot. Information in agriculture helps to take timely action, prepare strategies for next season or year, speculate the market changes, and avoid unfavourable circumstances. So, the development of agriculture may depend on how fast and relevant information is provided to the end users (farmers). Already there are traditional methods to provide the information to the end users. Mostly they are inoculated, untimed and also it will take long time to provide the information and get feedback from the end users.

So, now, it's time to look at the new technologies and methodologies, which will benefit developing our nation by implementing Information Technology to exchange the information through effective communication like
Information Kiosks which provide the basic services like email communication, helps in education, health services, agriculture and irrigation, online trading, community services etc. We also need expert systems which help in determining marketing alternatives and optimal strategies for farmers, integrated crop management systems for different crops, Farm-level Intelligent Decision Support System [1] for risk reduction in agriculture and efficient irrigated agriculture. Many Organizations and Institutes should utilize the information technology to provide solutions to the problems faced by the agriculture sector in a cost effective manner with proper business models. Still a lot of research has to happen in this area particularly in India.

To control something, objects of which the mechanisms are known, are easy to control, but it is quite difficult to control an object such as agriculture of which the mechanism cannot be particularly explained. Hence most tasks have to rely on human capability rather than technology. However, if there is a technique to control agriculture, one can expect steady and high-quality harvests.

\section{NEED AND IMPORTANCE OF RESEARCH PROBLEM}

Ideal farmers have tremendous skills and knowledge in cultivation. They know the timing to supply the suitable fertilizer and required amount of water in order to grow high quality and more abundant harvests. Farmers have acquired their knowledge through years of experience and also their talent. If agriculture can somehow be automated, that uses the farmer's expertise, people will perhaps enjoy good food more often and at reasonable prices.

Crops have the power to live on their own, and they grow under certain conditions but to a certain limit. Without any human intervention, crops will be of poor quality and low yield. That is the big difference between crops that grow in the wild and the ones grown by farmers. It is a matter of manipulating good conditions and environments for crops. Also, it is acceptable to have poor quality crops so long as we have a harvest, but it would be a problem if all the crops died in bad year, or all crops grew well in a successful year.

We believe that with the proposed Information System, it would be possible to consistently produce high-quality crops. The research would initially concentrate on the current mechanism of the Indian farmer in this regard. Then the information would be collected from the farmers of various regions in Andhra Pradesh and study the observations and judgments of experienced farmers in these regions. 
Table 1. Parameters taken as the basis for our research

\begin{tabular}{|c|c|c|}
\hline S.No & Parameter & Description \\
\hline 1 & $\begin{array}{l}\text { Sector } \\
\text { Status in } \\
\text { India }\end{array}$ & $\begin{array}{l}\text { - Growth of socio-economic sector in } \\
\text { India. } \\
\text { - Nearly about } 70 \% \text { of population } \\
\text { depend on agricultural sector. } \\
\text { - Agriculture sector occupied almost } \\
43 \% \text { of India's geographical area. }\end{array}$ \\
\hline \multirow[t]{2}{*}{2} & $\begin{array}{l}\text { Huge } \\
\text { Investment } \\
\text { made }\end{array}$ & $\begin{array}{l}\text { Huge investments in 11th Five } \\
\text { year plan(2007-12) [5]. }\end{array}$ \\
\hline & $\begin{array}{l}\text { De- } \\
\text { regulation } \\
\text { in } \\
\text { Agriculture } \\
\text { sector }\end{array}$ & $\begin{array}{l}\text { Establishment of private } \\
\text { markets/yards, direct purchase } \\
\text { centers, consumer /farmers' } \\
\text { markets for direct sale leads to } \\
\text { good price to farmer. } \\
\text { - To protect farmers from the } \\
\text { exploitation of intermediaries and } \\
\text { traders and also to ensure better } \\
\text { prices and timely payment for their } \\
\text { produce. } \\
\text { - Significant technology growth in } \\
\text { coming years. }\end{array}$ \\
\hline 4 & $\begin{array}{l}\text { Identified } \\
\text { areas for } \\
\text { Agriculture } \\
\text { sector }\end{array}$ & $\begin{array}{l}\text { Needs monitoring on agricultural } \\
\text { crop conditions, weather and } \\
\text { climate and ecosystem. }\end{array}$ \\
\hline 5 & $\begin{array}{l}\text { Decision } \\
\text { support } \\
\text { needed }\end{array}$ & $\begin{array}{l}\text { For agricultural planning and } \\
\text { policy making, plant production } \\
\text { system, plant classification, land } \\
\text { evaluation, control of green house } \\
\text { [2]. }\end{array}$ \\
\hline
\end{tabular}

\section{OBJECTIVES}

A good degree of accuracy may be ensured with plenty of data but not with a small amount of data. Therefore, reliability is not always assured. So, the decision support system [1] is to be developed using Experience Based Learning (previous experience or expertise in the field of agriculture) in order to overcome this problem. The fundamental idea, the farmer has to utilize the decision support system, so that they can yield effective outcome from agri-fields [2]. The reliability of the data is then computed on the difference between the actual and the similar one in the past.

For example, Agriculture involves various factors, such as nature, environment in a greenhouse, and human work. For this system to be successful, it is very important to select the necessary factors to utilize as data [3][4]. Just inputting data is not enough to produce an output. Therefore, it will be essential to set up a decision support system [1] in which specialists, such as experienced farmers and academicians researching the growth mechanism of plants or crops, cooperate in estimating the growth mechanism and processing related data.

If we could utilize Experienced Based Learning in analyzing and modeling collected data, then by using this approach, an attempt could be made to predict the output value from corresponding input values by referring to a base of past cases. In particular, the mechanism of agriculture is so complex, and this system would be useful for predicting future events from data. This is the point that totally differs from conventional control techniques where it works out estimated values from data and creates outputs, even though mechanism is not completely clear. To do so, just obtaining reliable data and utilizing sophisticated processing system are not enough. We need people to provide the data, or else the information processing ability would be wasted. Therefore, it is important to determine ways to collaborate with the specialists in the field of agriculture and the use of Experienced Based Learning concept to play a crucial role in agriculture of Andhra Pradesh in future.

\section{METHODOLOGY}

Our research hopes to apply Experienced Based Learning concept to agriculture, which involves complicated factors. In agriculture, expressing its mechanism using numerical models is difficult. So we gather samples of what will occur due to various phenomena, such as the effects of environmental control factors such as period of sunshine, water supply, temperature, humidity, rainfall, pests and soil salinity. Accumulating data of these variables helps us to predict what happens next and estimate the probability of occurrences although the mechanism remains unknown. The system therefore succeeds in acquiring the knowledge and imitating the actions of an experienced farmer.

\section{The objective of research:}

- To create an empirical research-based view of the agriculture practice in India in general and Andhra Pradesh in particular through studies and seminars, workshops and conferences.

- Through action research framing, appropriate systems development methods for agriculture information systems can be done taking into account the socio-economic impact, sustainability and community participation [6].

\section{Expected Outcome of research:}

- Conduct stakeholder assessments to better understand needs and expectations

- Evaluate the impact of environmental control factors on crops

- Informed and quick decision making to ensure profitable performance of the farmers.

\section{CONCLUSION}

The role of Information Technology to build up agriculture and life of people in rural areas is well ascertained. The agricultural expansion system is dependent on IT to provide appropriate and location specific technologies for the farmers to furnish timely and experts advices to the farmers but also to enhance research and education system in agriculture. A silent revolution is taking place in the communication systems with the help of Internet in rural India. A lot of work to be done to familiarize Internet usage to the farmers.

This research mainly recommend from socio-economic viewpoint on developing new computational models to solve complex problems in agriculture sector and also keep track of all type of information related to agriculture, so that will aid the farmers in increasing their productivity and also leading to their economic growth. The future scope is to incorporate innovative precision agriculture technologies into standard farming practices and by doing this, farmers, reasearchers and agriculturists will be able to identify the factors that influence crop productivity in order to provide an implemented solution for maximization of production across the country. 


\section{REFERENCES}

[1] Manpreet Singh,Parvinder Singh, and Sumitter Bir Singh,“ Decision Support System for Farm Management", World Academy of Science,Engineering and Technology 39, 2008.

[2] V.S.Janakiraman and K.Sarukeshi "Decision Support Systems" Prentice-Hall of India Private Limited,New Delhi,2001,pp.26-77.

[3] D.S.Bullock, ET AL., "Multidisciplinary teams: A necessity for research in precision agriculture systems", Crop Science, vol. 47, pp.1765-1769, 2007.
[4] A.Flores, "Speeding up Data Delivery for Precision Agriculture", Agric.Res.Mag.: The United State Department of Agriculture (USDA), VOL.51, NO.6, PP.17,20

[5] http://planningcommission.nic.in/plans/planrel/11thf.htm

[6] L.Pradhan, S.Dehuri, B B Mohapatra and A K Panda, "A Study of Computational Intelligence in Agriculture" 